\title{
Comparison of different windows for low-energy houses
}

\author{
Peter Juras ${ }^{1, *}$, Daniela Staffenova $^{1}$ and Pavol Durica ${ }^{1}$ \\ ${ }^{1}$ Department of Building Engineering and Urban Planning, Faculty of Civil Engineering, University \\ of Zilina, Univerzitna 8215/1, 01026 Zilina, Slovakia
}

\begin{abstract}
This paper deals with an outcome of long-term experimental measurement of windows suitable for low-energy or zero houses. Three different windows are evaluated since 2011 in the Laboratory of the Department of Building Engineering and Urban Planning, Faculty of Civil Engineering, University of Zilina. All windows have implemented triple glazing, but with various frame type. Two frames are made from plastic and one from wood. The plastic frames differ from each other with use of thermal insulation inside one of mentioned frames. The test room has adjustable indoor boundary conditions and is exposed to real outdoor climate conditions measured through the own detached experimental weather station. Temperatures and heat fluxes are continuously measured on glazings and frames. This paper compares the windows by the requirements of Slovak standard on the inner surface temperatures and differences of the thermal transmittance for glazing and sash.
\end{abstract}

\section{Introduction}

With the increased thermal insulation and protection of buildings it is also necessary to minimize the loss through the openings (windows, doors, etc.). Windows are complicated construction and during the research through the centuries made big advance in the technology basis, material and construction. On contrary to the non-transparent parts of the building envelope (roof, wall, etc.), window has more function than to isolate the harsh climate conditions and to protect the indoor climate and people. Primary function of windows is solar insulation of the space. Another crucial is air ventilation, contact with outdoor etc. With the more strict requirements of thermal properties it is necessary to increase the thermal properties of used materials, both for glazings (triple, gas fillings, heat mirrors and low emissivity surfaces) and frames (wooden, aluminium, plastic with thermo modules, more chambers etc.) Nonetheless is the advance with incorporating the photovoltaics into the glazing or usage of transparent thermal insulations [1,2].

The Slovak standard [3] dealing with thermal protection (STN 73 0540:2012) and EC directives regarding to the thermal protection outlines the requirements for windows and low energy houses. This article deals with testing of such windows, which meet the required properties for windows (valid from January $\left.2016-U_{\mathrm{w}}<1.0 \mathrm{~W} /\left(\mathrm{m}^{2} . \mathrm{K}\right]\right)$. Windows

\footnotetext{
*Corresponding author: peter.juras@fstav.uniza.sk
} 
in this experimental measurement were commercially available back than in 2011, where were built-in into the experimental laboratory of Department of Building Engineering and Urban Planning.

\subsection{Description of laboratory and measuring equipment}

The window constructions evaluated in this article are built into the testing laboratory of the Department. This is so-called laboratory of the pavilion type, which nowadays consists of three different rooms. Two of them contain lightweight timber framed wall [4]. In the third experimental room, there are three different windows built into the wall (Fig. 1). The windows are oriented to the south with slight declination to the west $\left(15^{\circ}\right)$. From outside, windows are exposed to the real climate boundary conditions. The outdoor climate is monitored and recorded by the detached experimental weather station placed on the nearby building`s roof [5]. Exact monitoring of outdoor boundary conditions in-situ enables the possibility for more precise measurement and simulations. The indoor climate is controlled by the AC unit, which is set to maintain the Slovak standard indoor boundary conditions: $20{ }^{\circ} \mathrm{C}, 50 \%$.

Set of sensors used for measurements itself contains of thermocouples [6] and heat flux plates [7]. Totally 36 thermocouples, uniformly placed on three windows on the critical places (contact between glazing and window sash, corners, etc.). That is 6 positions on each window and also each position consists of two sensors (one inside, one outside). There are two types of heat flux plates [7]. There are some standard ones $(120 \times 120 \mathrm{~mm})$ and half sized for window sashes and frames. Positions of thermocouples and heat flux plates are shown in Fig. 2.

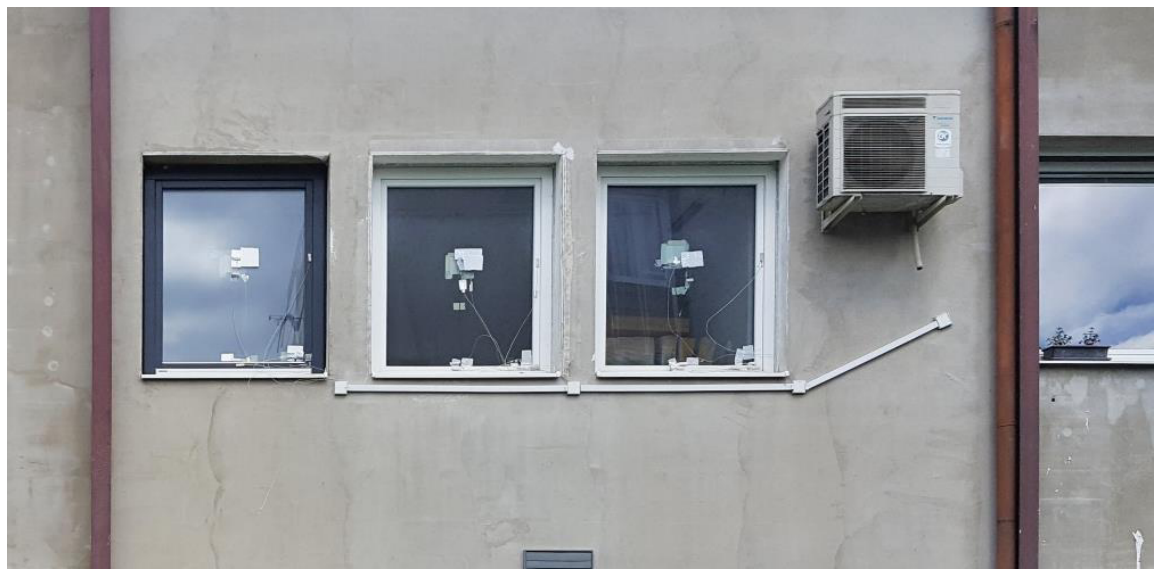

Fig. 1. Outside view on the three tested windows in the laboratory belonging to the Department of Building Engineering and Urban Planning. Southward façade, second floor

The datalogger and both sensor types are from Ahlborn. All the windows were built into the wall in 2011, equipped with thermocouples for monitoring the temperatures [5]. Since 2013 the outdoor climate has been monitored more precise by the experimental weather station [5]. Finally, from autumn 2015 there are also the heat flux plates (HFP) fixed on the inner surfaces, which creates the possibility to measure the heat flux and thermal conductance coefficient of the glass and frame, depending on the position of the plates. For needs of this article, seven HFP were used. Three of them have a standard dimensions, placed in the centre of glazing, three small ones placed on the windows sashes and another one on the frame (wooden window C). Positions are marked in Fig. 2. Each HFP measures the thermal flow and also the surface temperature. 

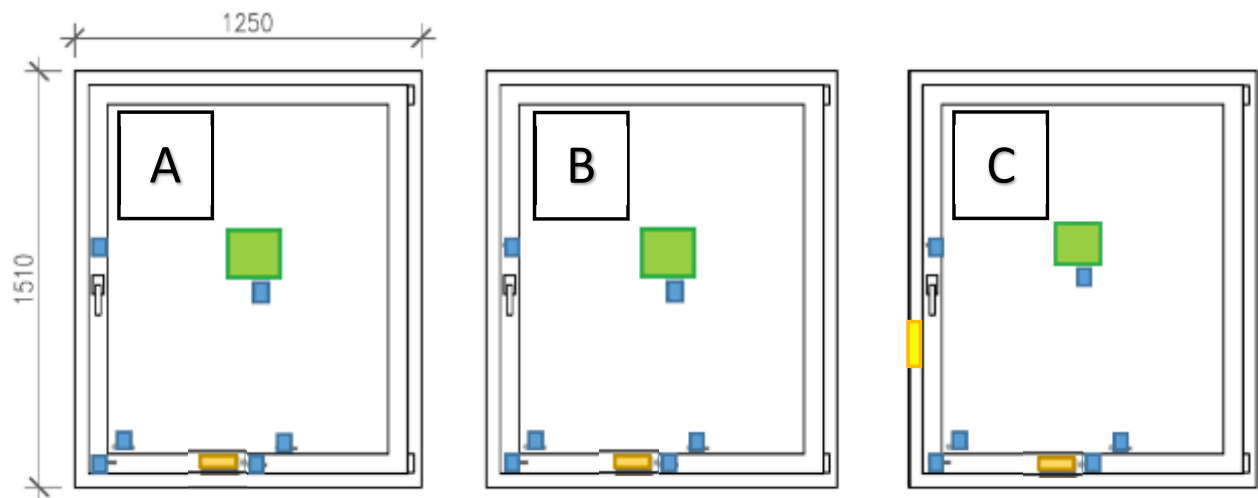

Fig. 2. Measuring sensors placement scheme (view from the interior) on the windows. Windows from left: A - plastic, B - plastic with thermal insulation (thermo modules), C - wooden. Small squares are thermocouples from both sides, HFP are placed from inside - centre of glazing and window sash. The last one is placed on the frame of window $\mathrm{C}$

\subsection{Description of measured windows}

As it was mentioned above, three different windows were long-time tested. Outside view is shown in Fig. 1 and a schematic view from inside is in Fig. 2. Windows are marked from left (from inside): window A: plastic, 6 chambers in profile; window B: plastic, 6 chambers in profile with integrated thermo modules (insulation in chambers). The last window is a wooden one with thickness of profile $78 \mathrm{~mm}$. It has declared best thermal properties of frame and slightly worse for glazing. Other parameters, such as gas filling, heat gain or calculated $U_{\mathrm{w}^{-}}$values are summarized in Tab. 1 .

Table 1. Properties of the measured experimental windows

\begin{tabular}{|c|c|c|c|c|c|c|c|c|c|}
\hline Window & Material & $\begin{array}{c}\text { No. of } \\
\text { chambers }\end{array}$ & Glazing & Gas & $\begin{array}{c}\text { Heat } \\
\text { gain }\end{array}$ & $U_{\mathrm{w}}$ & $U_{\mathrm{f}}$ & $U_{\mathrm{g}}$ \\
\hline & & & & & {$[\%]$} & \multicolumn{4}{|c|}{$\left[\mathrm{W} /\left(\mathrm{m}^{2} . \mathrm{K}\right)\right]$} \\
\hline $\mathrm{A}$ & plastic & 6 & triple & $\mathrm{Ar}$ & 36 & 0.8 & 1.0 & 0.5 \\
\hline $\mathrm{B}$ & $\begin{array}{c}\text { plastic with } \\
\text { thermo modules }\end{array}$ & 6 & triple & $\mathrm{Kr}$ & 47 & 0.78 & 0.85 & 0.5 \\
\hline $\mathrm{C}$ & wood & - & triple & $\mathrm{Ar}$ & 48 & 0.79 & 0.8 & 0.6 \\
\hline
\end{tabular}

\subsection{Measuring principle with use of heat flux plates}

The thermal transmittance coefficient ( $U$-value) of a structural element describes the quantity of thermal energy that passes through it from one side to the other per second and per square meter surface at a constant difference in ambient temperature of $1^{\circ} \mathrm{K}$. A constructions $U$-value (unlike its thermal conductance 1 ) includes the thermal transfer characteristics on its surfaces $\left(h_{i}\right.$ and $\left.h_{e}\right)$. The thermal transmittance coefficient of the structure is the reciprocal of its total thermal transmittance resistance $R_{\mathrm{o}} . R_{\mathrm{o}}$ is the sum of the thermal conductance resistances of the structure`s various contiguous layers plus the thermal surface transfer resistances between the structure and the ambient media on either side, in our case air on both sides. The relationship is shown in Eq.1:

$$
U=\frac{1}{R_{o}}=\frac{1}{\left(R_{s i}+R+R_{s e}\right)}=\frac{1}{\frac{1}{h_{i}}+\frac{1}{\Lambda}+\frac{1}{h_{e}}}=\frac{q}{\theta_{a i}-\theta_{a e}}
$$


$U$ - thermal transmittance coefficient $\left[\mathrm{W} /\left(\mathrm{m}^{2} . \mathrm{K}\right)\right]$

$R_{\mathrm{o}}$ - total thermal transmittance resistance $\left[\left(\mathrm{m}^{2} . \mathrm{K}\right) / \mathrm{W}\right]$

$R_{\mathrm{si}}$ - thermal surface transfer resistance on the inner surface $\left[\left(\mathrm{m}^{2} . \mathrm{K}\right) / \mathrm{W}\right]$

$R_{\mathrm{se}}$ - thermal surface transfer resistance on the outer surface $\left[\left(\mathrm{m}^{2} . \mathrm{K}\right) / \mathrm{W}\right]$

$R$ - thermal conductance resistance of all layers $\left[\left(\mathrm{m}^{2} . \mathrm{K}\right) / \mathrm{W}\right]$

$h_{\mathrm{i}}$ - surface coefficient of heat transfer, inside $\left[\mathrm{W} /\left(\mathrm{m}^{2} . \mathrm{K}\right)\right]$

$h_{\mathrm{e}}$ - surface coefficient of heat transfer, outside $\left[\mathrm{W} /\left(\mathrm{m}^{2} . \mathrm{K}\right)\right]$

$\Lambda$ - thermal conductance coefficient $\left[\mathrm{W} /\left(\mathrm{m}^{2} . \mathrm{K}\right)\right]$

The heat flux plate`s measuring principle is described in the Eq. 2:

$$
q=C \cdot U_{t h}
$$

$q$ - heat flow density $\left[\mathrm{W} /\left(\mathrm{m}^{2} \cdot \mathrm{K}\right)\right]$

$C$ - calibration constant of the heat flux plate $\left[\mathrm{W} /\left(\mathrm{m}^{2} . \mathrm{mV}\right)\right]$

$U_{\text {th }}$ - voltage measured by heat flux plate $[\mathrm{mV}]$

Thermal surface transfer coefficient can be calculated according to Eq. 3 and 4:

$$
\begin{aligned}
& h_{i}=\frac{q}{\theta_{s i}-\theta_{a i}} \\
& h_{e}=\frac{q}{\theta_{s e}-\theta_{a e}}
\end{aligned}
$$

$\theta_{\mathrm{si}}$ - temperature of inner surface $\left[{ }^{\circ} \mathrm{C}\right]$

$\theta_{\mathrm{ai}}$ - temperature of indoor air $\left[{ }^{\circ} \mathrm{C}\right]$

$\theta_{\text {se }}$ - temperature of outer surface $\left[{ }^{\circ} \mathrm{C}\right]$

$\theta_{\mathrm{ae}}-$ temperature of outdoor air $\left[{ }^{\circ} \mathrm{C}\right]$

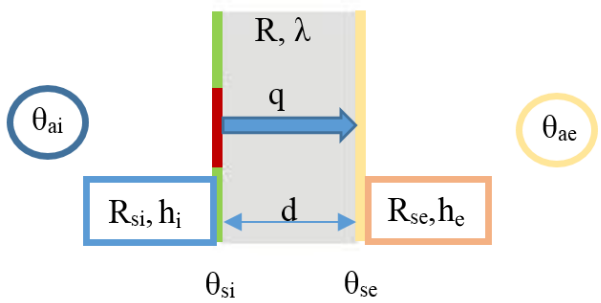

Fig. 3. Scheme of factors, which influence the heat flux through the structure

\section{Measurement results}

First result is overview of the surface temperatures - if they meet the Slovak standard for inner surface temperature for windows $\left(9.6^{\circ} \mathrm{C}\right)$ and the second one is a comparison of design or manufacturer values for frame and glass to the measured ones. Also cross comparison between the HFP itself is possible and among the measured surface temperatures from thermocouples and HFPs, too. Last comparisons are temperatures during the lifetime (2012-2017) of the windows.

\subsection{Surface temperatures}

For temperature measurement $28^{\text {th }}$ January 2017 (0:00-24:00) was chosen and graphs representing the courses of surface temperatures are shown in Fig. 4. The outdoor 
temperature during the night was almost steady for approximately $-12{ }^{\circ} \mathrm{C}$ and the day was a typically winter one with bright sky and a lot of sunshine. This can be seen on the surface temperatures high above $25^{\circ} \mathrm{C}$. Although it was freezing also during the whole day.
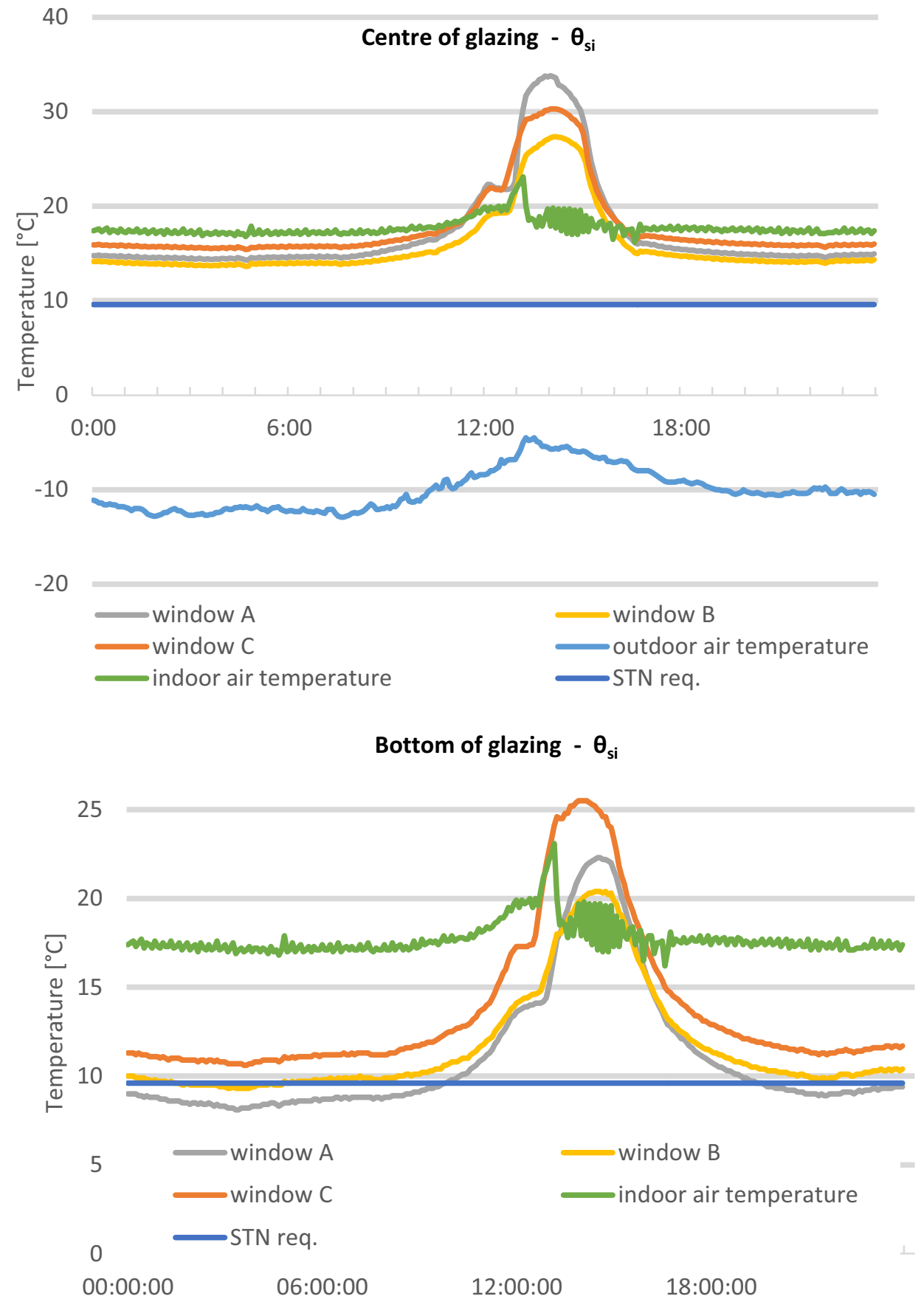

Fig. 3. Results of surface temperature measurement on $28^{\text {th }}$ January 2017 (0:00-24:00). Graph above represents a daily course for position in the centre of glazing and bottom's graph the worst position bottom of the glazing / contact with window sash. 


\subsection{Heat fluxes}

Heat flux measurement required following criteria: difference of temperatures as high as possible (up to $30{ }^{\circ} \mathrm{C}$ in this case), small fluctuations over the time period, no solar radiation (during night) and short time interval (5-minute time period used). For calculation of heat fluxes were selected two time periods, both on the $30^{\text {th }}$ January 2017 . The indoor and outdoor temperatures for these two periods are shown in Fig. 4.

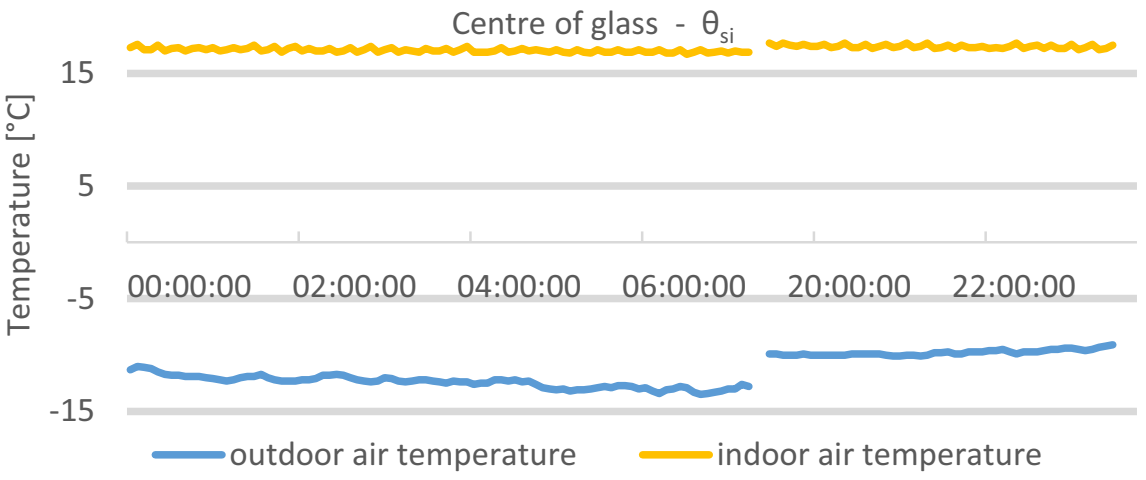

Fig. 4. Boundary conditions used for calculation of thermal surface transfer coefficient and thermal transmittance coefficient - night of $30^{\text {th }}$ January 2017 - almost steady outside temperature $-11^{\circ} \mathrm{C}$ and inside $18^{\circ} \mathrm{C}$

For calculation of the surface coefficient of heat transfer with use of HFPs, the Eq. 3 and 4 were used and the results for all HFP are summarized in the Tab. 2. The results show a big difference between measured and standard values in some cases (exterior mostly), which could be influenced by the measuring method itself, unsteady state, lower accuracy of the thermocouples or imperfect contact between the sensor and surface. For exterior coefficient has also high impact the unsteady condition of outdoor: wind and long wave radiation of night sky. It seems that a considerable uncertainty is also caused by the AC unit, because values differ with distance from AC unit outlet. In case of the surface temperature being measured by HFP and thermocouples $\left(h_{\mathrm{i}}\right)$, both values are stated in Tab. 2. Calculated heat fluxes in form of thermal conductance coefficient based on the measurement are shown in Tab. 3.

Table 2. Surface coefficient of heat transfer defined in the standard STN 730540 and the calculated one using Eq. 3 and 4.

\begin{tabular}{|c|c|c|c|c|c|c|c|}
\hline $\begin{array}{c}\text { surface coefficient } \\
\text { of heat transfer } \\
{\left[\mathrm{W} /\left(\mathrm{m}^{2} . \mathrm{K}\right)\right]}\end{array}$ & $\begin{array}{c}\text { STN } \\
73 \\
0540 \\
\end{array}$ & $\begin{array}{c}\text { A } \\
\text { glazing }\end{array}$ & $\begin{array}{c}\mathrm{B} \\
\text { glazing }\end{array}$ & $\begin{array}{c}\mathrm{C} \\
\text { glazing }\end{array}$ & $\begin{array}{c}\text { A } \\
\text { sash }\end{array}$ & $\begin{array}{c}\text { B } \\
\text { sash }\end{array}$ & $\begin{array}{c}\mathrm{C} \\
\text { sash }\end{array}$ \\
\hline$h_{\mathrm{i}}$ (thermocouples) & \multirow{2}{*}{7.62} & 7.95 & 6.63 & 15.1 & 4.0 & 3.9 & 4.9 \\
\hline$h_{\mathrm{i}}$ (HFP) & & 10.3 & 8.1 & 8.1 & 4.7 & 4.9 & 6.1 \\
\hline$h_{\mathrm{e}}$ & 25 & 13.7 & 5.96 & 8.2 & 6.8 & 6.65 & 7.5 \\
\hline
\end{tabular}

Table 3. Measured heat fluxes in form of thermal conductance coefficient $\left[\mathrm{W} /\left(\mathrm{m}^{2} . \mathrm{K}\right)\right]$

\begin{tabular}{|c|c|c|}
\hline Window & Frame $\left[\mathrm{W} /\left(\mathrm{m}^{2} . \mathrm{K}\right)\right]$ & Glazing $\left[\mathrm{W} /\left(\mathrm{m}^{2} . \mathrm{K}\right)\right]$ \\
\hline A & 0.76 & 0.9 \\
\hline B & 0.73 & 1.05 \\
\hline C & 0.65 & 0.67 \\
\hline
\end{tabular}




\subsection{Temperature comparison through the years of measurement}

The windows are constantly measured since 2011. In the Tab. 4 there are compared results of average surface temperatures (both positions: centre of the glazing and the worst position based on the research - bottom of the glazing). Through the years there were selected specific hours during the year with similar outdoor air temperature (minimal 10 values, that are $10 \times 15$ minutes interval, during night). One of the comparative temperature is $-14.2{ }^{\circ} \mathrm{C}$ (values from years 2012, 2014, 2016 and 2017) and second one is $-21,2{ }^{\circ} \mathrm{C}(2012$ and 2017).

Table 4. Measured values of surface temperatures during years with similar outdoor and indoor air temperatures

\begin{tabular}{|c|c|c|c|c|c|c|c|c|c|}
\hline $\begin{array}{c}\text { Outdoor air } \\
\text { temperature }\end{array}$ & Year & \multicolumn{6}{|c|}{ Windows Glazing } & \multicolumn{3}{|c|}{ Windows Sash } & $\begin{array}{c}\text { Indoor air } \\
\text { temperature }\end{array}$ & $\begin{array}{c}\text { Measured } \\
\text { values }\end{array}$ \\
\hline$\left[{ }^{\circ} \mathrm{C}\right]$ & & $\mathrm{A}$ & $\mathrm{B}$ & $\mathrm{C}$ & $\mathrm{A}$ & $\mathrm{B}$ & $\mathrm{C}$ & {$\left[{ }^{\circ} \mathrm{C}\right]$} & {$[\mathrm{n}]$} \\
\hline-14.3 & 2012 & 14.8 & 14.6 & 16.4 & 7.7 & 9.5 & 10.3 & 18.8 & 10 \\
\hline-14.2 & 2014 & 15.1 & 14.6 & 16.4 & 8.5 & 10.0 & 10.8 & 19.1 & 11 \\
\hline-14.3 & 2016 & 14.4 & 14.4 & 16.2 & 7.7 & 9.5 & 10.4 & 18.9 & 14 \\
\hline-14.2 & 2017 & 13.1 & 13.0 & 14.9 & 7.1 & 8.6 & 9.1 & 16.7 & 30 \\
\hline \hline-21.2 & 2012 & 13.8 & 13.4 & 15.4 & 5.0 & 6.7 & 8.4 & 18.7 & 10 \\
\hline-21.2 & 2017 & 11.6 & 11.6 & 13.7 & 3.7 & 5.0 & 6.6 & 15.8 & 22 \\
\hline
\end{tabular}

\section{Results and discussion}

Results from surface temperatures measurement are shown in Fig. 3. All points on the windows have to meet the surface temperature higher than $9.6{ }^{\circ} \mathrm{C}$, which is required by STN 73 0540:2012. In this paper, there are presented courses for two positions from six measured. Centre of glazing, where the value should not be influenced by the sash or frame. Based on former research, the worst position is the contact between glazing and sash, but not in the corner but at the bottom.

From the courses it is clear, that for the first case all windows meets the required value and overestimate it about $5{ }^{\circ} \mathrm{C}$. Another case is the second position. The temperature for the window $\mathrm{A}$ is low during the whole night (outdoor air temperature around $-12{ }^{\circ} \mathrm{C}$ ), for window $\mathrm{B}$ the outdoor air temperature around $-13{ }^{\circ} \mathrm{C}$ would be critical. The wooden window $\mathrm{C}$ stays above the limit with reserve. If the temperature fell down more (lowest than $-16 \sim-17^{\circ} \mathrm{C}$ ) there is a high possibility to underpass the required value. On the other hand, the indoor air temperature oscillated during the night at around $18.5^{\circ} \mathrm{C}$ instead of 20 ${ }^{\circ} \mathrm{C}$, which is defined in the standard. Defined outdoor air temperature for Zilina in the standard is $-15^{\circ} \mathrm{C}[3]$.

Heat fluxes calculated as a ratio between heat flux and differences between air temperatures (Eq. 1) in the form of $U$-values $\left[\mathrm{W} /\left(\mathrm{m}^{2} . \mathrm{K}\right)\right]$ are summarized in Tab. 3. These values cannot be strictly compared to the design values $\left(U_{\mathrm{f}}\right)$ because of the unsteady thermal state. The results of sash itself take into account the glazing, so the heat flux is deformed and influenced by the edge of glazing, spacer etc. On the other hand, the design values are measured according to the STN EN 12412-2 in the climate chamber equipped with hotbox in steady state. By the window A, the heat flux through the glazing is far worse than by the window B or C. $U_{\mathrm{g}}$ values from manufacturers (Tab. 1) should be almost the same. Only the window $\mathrm{C}$ is close to the design value and with best results, which is also shown in the surface temperature results. According to the window sashes, best is the wooden window followed by the plastic window with thermo modules. These modules slightly increased the $U_{\mathrm{f}}$, but it cannot be calculated exactly because of the uncertainty 
during measurement. As mentioned above, the correct comparison of $U$-values cannot be made by the unsteady thermal state and the difference between measurement in situ and in the laboratory.

Long-time measurement results comparison in the Tab. 4 shows very similar results through the years of measurements. Windows A and B had problem to meet the requirements for the critical position - bottom of the glazing. It should be noted, that the indoor air temperature was lower, typically $1-2{ }^{\circ} \mathrm{C}$ than the required one $20{ }^{\circ} \mathrm{C}$. For example, critical temperature for the air temperature $18{ }^{\circ} \mathrm{C}$ is only $7.8{ }^{\circ} \mathrm{C}$ [3]. With the outdoor air temperature around $-21^{\circ} \mathrm{C}$ is the sash of window A really cold, but again, the indoor temperature was lower than $20^{\circ} \mathrm{C}$.

The results of temperature measurement presented in Fig. 3 and Tab. 4 show that in the centre of glazing the surface temperature is above the required standard even though the outside temperature was lower. In the lower corner, the temperatures are above the standard as well, but not with such limit than before. This is not surprising. Surprising are the results on the bottom of glazing, because both plastic windows, which should be suitable for passive buildings, did not reach the required temperature, so there is a possibility of dew occurrence or condensation of water vapour. The problem with measured temperatures could be caused by the $U_{\mathrm{g}}$ value, according to the results in Tab. 3, where it could be clearly seen that the measured value is $70 \%$ lower than the designed one (without taking into account the unsteady temperature of exterior air creating unsteady thermal state). This finding supports the idea that the window probably lost the gas filling in the glazing.

\section{Conclusions}

Presented results could be confusing. All windows should meet the requirements for use in low-energy houses, but results of long-time measurement show big differences between the design values of the plastic windows, especially in the glazing, which caused that the surface temperature at the bottom of the glazing did not meet the Slovak standard requirement. It should be noted again, that this type of measurement causes mistakes itself and the measured heat fluxes cannot be compared to the declared ones exactly, but the practical outcome and comparison between windows is significant. Results from the measurement show that both plastic windows did not meet the requirement of the Slovak national standard STN 73 0540:2012 in terms of minimal surface temperature. With such low temperatures at bottom of the glazing is very high probability of vapour condensation. On the other hand, the wooden window $\mathrm{C}$ reached good results for the glazing $U$-value and also for surface temperatures on the frame/ sash and glazing, so it proves its design values in the experimental measurement.

The research is supported by the research project VEGA No. 1/0729/13 and VEGA No. 1/0945/16

\section{References}

1. S. Kumar Pal et al., Appl. Energy 162, 11-20 (2016)

2. A. Hepbasli et al.: J. Estech. (to be published)

3. Slovak standard STN 730540:2012, Parts 1, 2, 3, SUTN Bratislava (2012)

4. P. Durica et. al. Procedia Eng. 111, 176-182 (2015)

5. D. Staffenova et. al., Adv. Mat. R. 1041 129-134, (2014)

6. NiCr-Ni thermocouple T190-0, website < http://ahlborn.com/getfile.php?2052.pdf> 
7. Thermal Flux Plates, website

$<$ http://www.ahlborn.com/download/pdfs/kap13/WflPlatten.pdf $>$ 